\title{
Immunologic Biomarkers and Biomarkers for Immunotherapies in Gastrointestinal Cancer
}

\author{
Benedikt Martin Bruno Märkl \\ Institute of Pathology, University Clinic Augsburg, Augsburg, Germany
}

Keywords

Gastrointestinal cancer · Colon cancer · Biomarker ·

Immunotherapy $\cdot$ Immunoscore

\section{Abstract}

Gastrointestinal (GI) cancers contribute significantly to the worldwide cancer burden. Pathologic evaluation is indispensable for the estimation of prognosis and therapeutic strategy. At present, immunotherapies are evolving into efficient therapeutic approaches, which are accompanied by the need for biomarkers to predict therapy response. In colorectal cancers, the only predictive biomarker for Food and Drug Administration-approved immunotherapy is the mismatch repair status. Besides, pathogenic polymerase epsilon mutations, tumor mutational burden, neoantigen load, and features of the immune contexture could soon find their way into clinical routine. Furthermore, in colorectal cancer, the Immunoscore, which is defined by the amount of CD3+ and CD8+ T-cells in the tumor center as well as at the infiltrative margin, might supplement the TNM system in the future (as TNM-Immune). This immunologic biomarker was shown to be impressively prognostic and predictive in colorectal cancer. In conclusion, there is increasing evidence of immunologic as well as predictive biomarkers for immunotherapies in Gl cancers. Nevertheless, future progress is necessary for the variety of current advances to be implemented in clinical care.

c 2019 S. Karger AG, Basel

\section{Introduction}

It is estimated that about 14.1 million new malignant tumors occurred in 2012 worldwide. Approximately 6 million of them occurred in developed countries, and about one of five was of gastrointestinal (GI) origin (colorectal, gastric, liver, or pancreatic cancer) [1]. In developed countries, almost every primary cancer diagnosis is based on pathologic evaluation. Besides the diagnosis, the main task of pathologic evaluation is the prediction of the clinical course to facilitate an adequate therapeutic approach. Especially for personalized medicine, biomarkers are of increasing importance. The AJCC/UICC TNM classification and histomorphologic assessment are still the backbone of risk stratification, but during the last years, the pathologist's repertoire has been supplemented. In particular, genetic biomarkers have paved the way to targeted therapies [2]. Now, immunotherapies are evolving into established therapies. The first immunologic treatment attempts were already carried out during the end of the 19th century, and Smith postulated a role of the immune system in cancer just a few years later [3, 4]. Nevertheless, advances in recent history have placed immunotherapies and the tumor-immune system interaction in the current limelight of cancer research. In 2013, the

B. Märkl: ORCID iD 0000-0002-7704-850X; B. Martin: ORCID iD 00000002-2314-3261.

\section{KARGER}

() 2019 S. Karger AG, Basel
Bruno Märkl

Department of Pathology, Institute of Pathology, Klinikum Augsburg Stenglinstrasse 2

DE-86156 Augsburg (Germany)

E-Mail bruno.maerkl@klinikum-augsburg.de 
journal Science selected cancer immunotherapy as "breakthrough of the year" [5]. The importance of this development was definitely documented by awarding the Nobel Prize 2018 to James P. Allison and Tasuku Honjo for their fundamental contributions in this field [6]. The different targets and strategies of immunotherapy have been described in excellent reviews by Stein et al. [7], Procaccio et al. [8], and Sanmamed and Chen [9] and are only briefly described herein. According to Sanmamed and Chen [9], immunotherapies can be divided into concepts that enhance the immune system and strategies that normalize or restore the immune response to cancer. Enhancers comprise interferons, interleukins, anti-CTLA4 antibodies, and the very recently introduced genetically engineered T-cells (e.g., CAR-T). These therapies are hampered by high rates of immune-related adverse events. Normalizing or restoring concepts aim to release the brake of the immune response to activate its natural function. This can be realized by application of antibodies against the programmed death receptor 1 (PD-1) or its ligand (PD-L1).

Now, 5 years after the proclaimed breakthrough of the year 2013, we will discuss in this article the role of immunologic biomarkers as well as biomarkers for immunotherapies in GI cancers. Because of its outstanding model role, we will mainly focus on colorectal cancer.

\section{Overview of Biomarkers in Immuno-Oncology}

Like other biomarkers in oncology, immunologic biomarkers can be either prognostic or predictive. In many circumstances they are both. The most investigated prognostic immunologic marker is the occurrence of infiltration of a tumor by immune cells. Tumor-infiltrating lymphocytes have gained the highest relevance in many cancer entities. High numbers of cytotoxic T-cells are effective in establishing immune surveillance that is countable by conventional histology and immunohistochemistry. Despite the currently high importance of tumor-infiltrating lymphocytes, other immune cells such as eosinophilic or neutrophilic granulocyte, macrophages, and dendritic cells could also be shown to be prognostic [10-13]. Recently, our group suggested lymph node size as a potential new and very easy evaluable marker for immune response, with enlarged lymph nodes indicating an enhanced response against a tumor $[14,15]$.

Since the indications of immune system-enhancing therapy regimens such as anti-CTLA 4 antibody and engineered T-cell administration are not based on biomarkers, the topic of predictive biomarkers in immunotherapy can be restricted to anti-PD-1 and anti-PD-L1 therapies. There are several possible strategies to estimate the chance of a response to anti-PD/anti-PD-L drugs (Table 1). First, the number of cells expressing those receptors or ligands can be measured. Currently, this is the main method to predict the response of the several antibodies that have entered clinical routine. More precisely, the PD-L1 scored by immunohistochemistry is of interest, although PD-L2 would have been another possibility for the prediction. PD-L1 assessment is a big matter of debate, and based on the substances and entities, there exist different ways how it has to be evaluated (Table 2). Those differences concern the cells that are counted and the cutoffs in different therapy lines. In the US, the antibodies and the technical platforms are specified by the Food and Drug Administration (FDA).

A second way to predict the likelihood of a therapy response is to identify features of a tumor that cause a particularly strong immune response. It is currently widely accepted that the production of neoantigens by a tumor is associated with a strong immune response. Tumors with a high number of mutations are more likely to produce such neoantigens. Mismatch repair-deficient (dMMR) tumors are also known to induce a particularly intensive immune response very likely due to the production of neoantigens. Table 1 gives an overview of established, upcoming, and potential biomarkers.

\section{Colorectal Cancer}

The field of immuno-oncology has gained an extraordinary dynamic with the development of several substances targeting different structures that have entered daily routine. Moreover, there are many other promising drugs and combination therapies in the pipelines of the pharmaceutical companies. Generally, its principles are applicable in all cancer types, including carcinomas, hematologic neoplasia, primary tumors of the central nervous system, and sarcomas [16]. This dynamic is also recognizable in GI cancers. Because of its outstanding model role, we mainly focus on colorectal cancer. In addition to the histomorphologic classification of colon cancer, there are several ways to subtype colon cancers. For example, it is possible to distinguish four molecular subtypes: the DNA mismatch repair capability of the tumors (mismatch repair-proficient [pMMR] versus dMMR tumors), the CpG island methylation phenotype, or the level of chromosomal instability $[17,18]$. The heterogeneity of colon cancer already indicates that personalized immunotherapies, with the need for predictive biomarkers, have to be implemented to offer an effective therapeutic approach.

\section{Predictive Biomarkers for Immunotherapies}

The first therapy approaches with PD-1 inhibitors were discouraging as no objective response was seen [19]. 
Table 1. Established, upcoming, and potential predictive biomarkers for checkpoint inhibitor therapies

\begin{tabular}{|c|c|c|c|c|c|}
\hline Biomarker & Method & Routine use & Remarks & $\begin{array}{l}\text { Relevance in GI } \\
\text { cancers }\end{array}$ & Reference \\
\hline PD-L1 & IHC & established & $\begin{array}{l}\text { several different cutoffs and } \\
\text { analysis guidelines }\end{array}$ & $\begin{array}{l}\text { ESC, GC, GEJC, AC, } \\
\text { HCC }\end{array}$ & Hazama et al. [53] \\
\hline Microsatellite instability & PCR & established & $\begin{array}{l}\text { approval by the FDA, } \\
\text { but not yet by the EMA }\end{array}$ & $\begin{array}{l}\text { especially for CRC, } \\
\text { but tumor agnostic } \\
\text { in general }\end{array}$ & Le et al. [21] \\
\hline Mismatch repair deficiency & IHC & established & $\begin{array}{l}\text { approval by the FDA, } \\
\text { but not yet by the EMA }\end{array}$ & $\begin{array}{l}\text { especially for CRC, } \\
\text { but tumor agnostic } \\
\text { in general }\end{array}$ & Le et al. [21] \\
\hline Tumor mutational burden & NGS & upcoming & $\begin{array}{l}\text { CheckMate } 026 \text { trial revealed } \\
\text { superiority over PD-L1 testing; } \\
\text { also relevant in SCLC and } \\
\text { urothelial cancer }\end{array}$ & not yet & $\begin{array}{l}\text { Schumacher and Schreiber } \\
\text { [29]; Yaghmour et al. [60]; } \\
\text { Buchhalter et al. [61] }\end{array}$ \\
\hline POLE & PCR & upcoming & & unclear & van Gool et al. [62] \\
\hline PD-L2 & IHC & potential & & unclear & $\begin{array}{l}\text { Schmid et al. [63]; Yearley } \\
\text { et al. [64] }\end{array}$ \\
\hline PD-L1/2 amplification & FISH & potential & & unclear & Inoue et al. [65] \\
\hline T-cell repertoire & $\begin{array}{l}\text { NGS, } \\
\text { nCounter }\end{array}$ & potential & & unclear & $\begin{array}{l}\text { McGranahan et al. [66]; } \\
\text { Newman et al. [67]; } \\
\text { Wallden et al. [68] }\end{array}$ \\
\hline Human papillomavirus & PCR & potential & virus-induced inflammation & unclear, perhaps AC & Hong et al. [69] \\
\hline Epstein-Barr virus & $\begin{array}{l}\text { IHC, ISH, } \\
\text { PCR }\end{array}$ & potential & virus-induced inflammation & GC & Kelly [70] \\
\hline
\end{tabular}

AC, anal cancer; CRC, colorectal cancer; EMA, European Medicines Agency; ESCA, esophageal squamous cancer; FDA, Food and Drug Administration; FISH, fluorescence in situ hybridization; GC, gastric cancer; GEJC, gastroesophageal junction cancer; GI, gastrointestinal; HCC, hepatocellular carcinoma; IHC, immunohistochemistry; ISH, in situ hybridization; NGS, next-generation sequencing; PCR, polymerase chain reaction; PD-L1, programmed death ligand 1; PD-L2, programmed death ligand 2; POLE, polymerase epsilon; SCLC, small-cell lung cancer.

Table 2. Overview of TPS, CPS, and ICS

\begin{tabular}{|c|c|c|c|}
\hline Score & Definition & Cutoff & Category \\
\hline TPS & $\mathrm{TPS}=\frac{\text { number of PD-L1-pos. TC }}{\text { total number of TC }} \times 100[\%]$ & $\begin{array}{l}>50 \% \\
>25 \% \text { and }<50 \% \\
>10 \% \text { and }<25 \% \\
>5 \% \text { and }<10 \% \\
>1 \% \text { and }<5 \% \\
<1 \%\end{array}$ & $\begin{array}{l}\text { Cologne } 5 \\
\text { Cologne } 4 \\
\text { Cologne } 3 \\
\text { Cologne } 2 \\
\text { Cologne } 1 \\
\text { Cologne } 0\end{array}$ \\
\hline CPS & $\mathrm{CPS}=\frac{\text { number of PD-L1-pos. TC }+ \text { number of PD-L1-pos. IC }}{\text { total number of TC }} \times 100$ & $\begin{array}{l}>10 \% \text { (urothelial/renal cancer) } \\
>1 \%(\text { GI/breast cancer }) \\
>1 \%\end{array}$ & \\
\hline ICS & ICS $=\frac{\text { area of PD-L1-pos. IC }}{\text { tumor area }} \times 100[\%]$ & $\begin{array}{l}>10 \% \\
>5 \% \text { and }<10 \% \\
>1 \% \text { and }<5 \% \\
<1 \%\end{array}$ & $\begin{array}{l}\text { IC } 3 \\
\text { IC } 2 \\
\text { IC } 1 \\
\text { IC } 0\end{array}$ \\
\hline
\end{tabular}

CPS, combined proportion score; GI, gastrointestinal; IC, immune cells; ICS, immune cell score; PD-L1, programmed death ligand 1; pos., positive; TC, tumor cells; TPS, tumor proportion score. 
Nevertheless, soon afterward studies elucidated that PD-1 inhibitor therapy was beneficial in metastatic dMMR colorectal cancer [20]. A phase II study with pembrolizumab, a PD-1 inhibitor, proved that the effectiveness of the immunotherapy depends on the mismatch repair status. None of the pMMR tumors responded to therapy, while dMMR tumors responded to a considerable extent [21]. Additionally, pembrolizumab was approved by the FDA in all solid dMMR tumors since it could be shown that deficient mismatch repair is predictive for treatment response, regardless of tumor origin [22]. Likewise nivolumab, another PD-1 inhibitor, is effective in metastatic dMMR colorectal cancer [23]. Biologically, dMMR tumors are predisposed for checkpoint inhibitor therapy as they are in particular dependent on checkpoint molecules [24]. Irrespective of that, the mentioned pembrolizumab studies also indicate that the number of somatic mutations and neoantigens play a central role in the effectiveness of PD-1 inhibitor therapy. High somatic mutation loads, a feature of dMMR tumors, were associated with prolonged progression-free survival [21]. Furthermore, T-cell clones that were reactive to mutant neopeptides were found in the tumor [22]. These findings are in alignment with other observations. In several indications, an increase in the tumor mutational burden has been associated with response to checkpoint inhibitor therapy [25-27]. Fabrizio et al. [28] recently identified in a cohort of 6,004 patients with colorectal carcinomas nearly $3 \%$ with pMMR tumors and high mutational burden. These patients could benefit from PD-1 inhibitor therapy, as do patients with dMMR tumors. Biologically, somatic mutations can generate neoantigens, which can be recognized by the host immune system [29]. Nevertheless, it has to be taken into account that the tumor-immune system interaction is complex. Galluzzi et al. [30] highlight that immunogenic cell death is dependent on antigenicity and adjuvanticity. According to that, the number of somatic mutations and neoantigens is just one of the two key factors.

Mutations in the polymerase epsilon (POLE) gene may serve as another potential predictive biomarker for PD-1 inhibitor therapy. About $1 \%$ of colorectal carcinomas harbor pathogenic somatic POLE mutations [31]. These $P O L E$-mutated tumors also exhibit a hypermutated genome although they are pMMR tumors. Therefore, POLE mutations could function as another predictive biomarker for PD-1 inhibitor therapy. The first case of a clinical response of a metastasized, POLE-mutated colorectal carcinoma to pembrolizumab has already been published [32].

The predictive value of tumor-infiltrating lymphocytes regarding immunotherapy is not well established. One study described an association between tumor-infiltrating CD8+ T-cells and response to $\mathrm{PD}-1$ inhibitory therapy in dMMR colorectal carcinomas [21]. However, this is in contrast with the observations in most other solid tumors [33].

Taken together, the mismatch repair status is an established predictive biomarker for treatment response for PD-1 inhibitor therapy in metastatic colorectal carcinoma. Tumor mutational burden as well as POLE mutations possess predictive value, but are not yet established as predictive biomarkers for PD-1 inhibitor therapy. Nevertheless, it can be assumed that in the near future, at least part of these biomarkers will find their way into routine clinical practice.

\section{Immunologic Biomarker: Immunoscore}

In 2006, the first landmark study was published by Galon et al. [34]. The group characterized immunologically a large cohort of human colorectal cancers by in situ immunohistochemistry as well as gene expression profiling. To summarize, it can be noted that the immunologic data outperformed the histopathologic prognostic factors for patient survival. Furthermore, similar results could be shown for the predictive value of CD8+ T-cells according to recurrence and patient survival [35]. The superiority might be explained by an inverse correlation of the immune infiltrate density (a positive prognostic factor) with the T classification, but constantly low immune infiltrate density in patients with relapsing early-stage tumors [35, 36]. Additionally, the predictive and prognostic value for tumor recurrence and survival could be shown for earlystage colorectal cancer as well as for rectal cancer [35, 37, 38]. In rectal cancer tumor biopsies, a high infiltration of CD3+ and CD8+ T-cells was associated with downstaging after chemoradiotherapy [38]. Additionally, the immune contexture was shown to be predictive for response to radiochemotherapy $[39,40]$. Noteworthy, the prognostic value of the Immunoscore is independent of the microsatellite status [41, 42].

To sum up, these studies underscore the impact of the immune contexture, which is defined as type, functional orientation, density, and location of adaptive immune cells within distinct tumor regions [36, 43]. Based on these findings the Immunoscore was developed. It consists of a standardized immunohistochemical evaluation of T-cells (CD3+ and CD8+ cells) in the tumor center as well as the infiltrative margin [36]. A worldwide taskforce was already founded 2012 to evaluate and validate the Immunoscore [44]. The Immunoscore could be a new approach to classify cancer, designated as TNM-Immune [45-47]. In Mai 2018 the results of the international validation study of the consensus Immunoscore for the classification of colon cancer were published [48]. Tissue samples from 2,681 patients were included in the analyses (training set: 700 patients; internal validation set: 636 patients; external validation set: 1,345 patients).
Visc Med 2019;35:3-10 DOI: $10.1159 / 000496565$
Martin/Märkl 
Fig. 1. a Schematic illustration of an epithelial cancer with a strong immune response consisting of plasma cells, lymphocytes, neutrophilic granulocytes, and histiocytes. b Tumor proportion score (TPS). Only the PD-L1-positive (membranous expression) tumor cells are counted. Immune cells stay unscored. c Combined proportion score (CPS). PD-L1-positive (membranous expression) tumor cells plus lymphocytes and histiocytes (membranous and/or cytoplasmic expression) are scored. The score has no dimension, the maximum value is 100 by definition. d Immune cell score (ICS). Only immune cells, including plasma cells and granulocytes, that cover the tumor area are counted. The score dimension of this score is percentage of area.
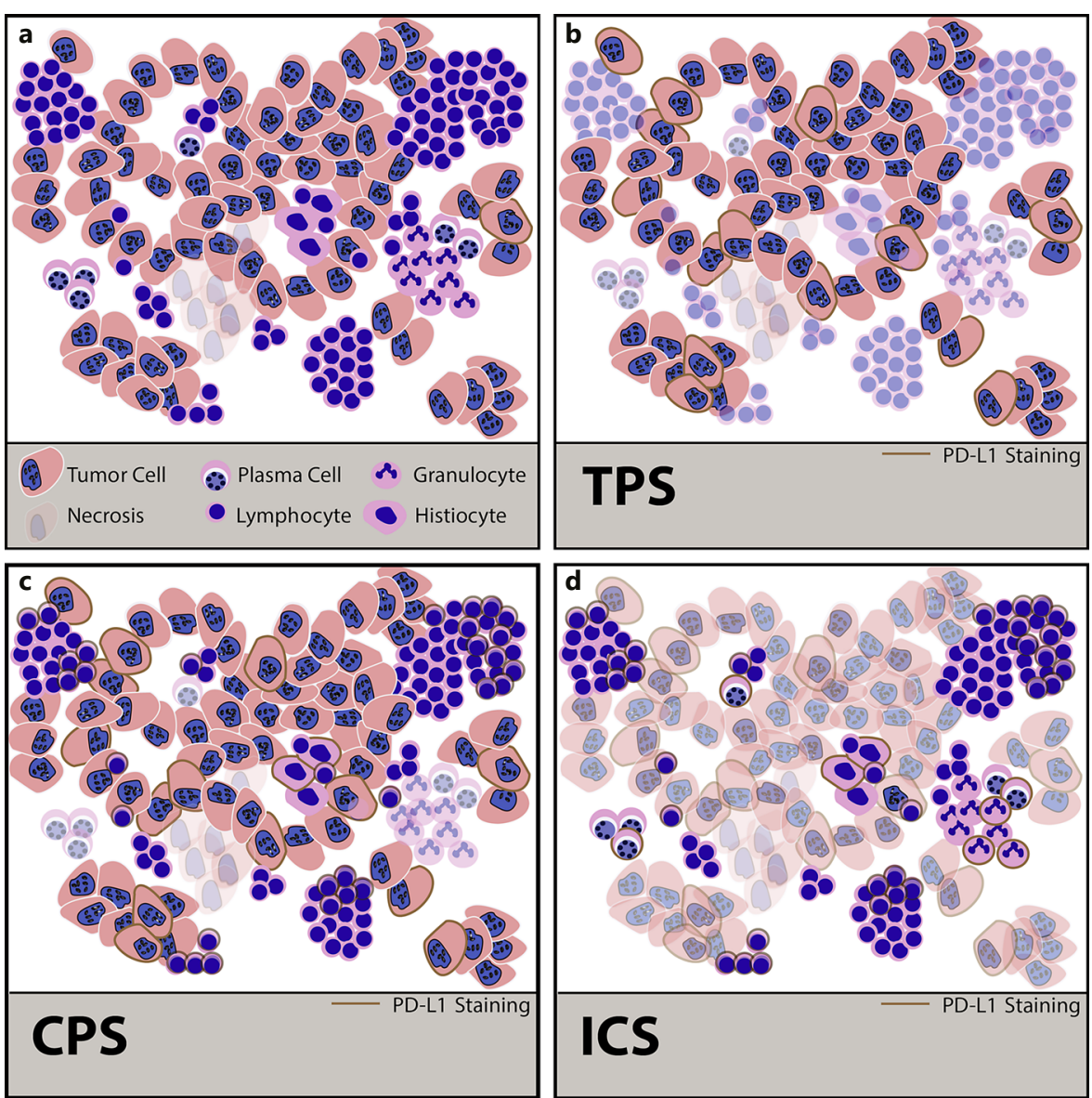

The results confirm a high level of reproducibility as well as the prognostic relevance of the Immunoscore. The hazard ratio for recurrence was only 0.2 for patients with a high versus low Immunoscore in the training set (95\% CI $0.10-0.38 ; p<0.0001$ ). Eight percent of patients with a high Immunoscore had a recurrence at 5 years, in contrast to $19 \%$ with a low Immunoscore. These findings could also be confirmed in the two validation sets. Moreover, the Immunoscore had the highest relative contribution to the risk of all clinical parameters and existing prognostic factors. In a subpopulation of patients with UICC stage II cancer, the Immunoscore was also able to perform a risk stratification for recurrence at 5 years (hazard ratio for high versus low Immunoscore 0.33, 95\% CI $0.21-0.52 ; p<0.0001)$. In conclusion, the authors state that the results support the implementation of the consensus Immunoscore as a new component of a TNMImmune classification of cancer [48]. Indeed, the results are promising and support the introduction in the evaluation of colon cancer. As the results were just recently published, it remains to be seen whether the Immunoscore becomes implemented in general recommendations and guidelines.

\section{Immunologic Biomarker: Lymph Node Size}

Recently, our group suggested lymph node size as a surrogate marker for the immune response in colon cancer. Lymph node enlargement is associated with an increased number of intratumoral lymphocytes and with favorable outcome $[14,49,50]$. Moreover, it correlates with the number of detected lymph nodes. Several findings indicate that that prognostic effect of lymph node count is not a stage migration effect, also called Will Rogers phenomenon. Instead, its true explanation is likely that the status of the immune response against the tumor is expressed in lymph node size [51].

\section{Other GI Cancer Types}

Because of its high incidence and prevalence, colorectal cancer is of importance and attracts major attention. However, other GI cancers occur less frequently but show more aggressive behavior than colorectal cancers, with 5 -year survival rates between 9 and 31 months [52]. This causes an urgent need for improved therapy regimens.

It is beyond this review that focuses on biomarkers to discuss all these new substances and ongoing studies. In 
the following, we will only give a rough overview. Concerning the details we refer to recently published excellent reviews that summarize the clinical aspects of immunooncology in GI cancers [7-9, 53].

Again, checkpoint inhibitors are the only immunotherapy concept that currently reaches praxis. Since the effectivity of pembrolizumab inhibitors has been proven in 12 entities other than colon cancer, the FDA approved pembrolizumab tumor agnostically for all microsatelliteunstable or dMMR-positive cases [21].

Beyond their important role in microsatellite-unstable/dMMR tumors, checkpoint inhibitors gain importance in GI cancers independent from mismatch repair status. Nivolumab received FDA approval in hepatocellular carcinoma [54] and pembrolizumab in gastric and gastroesophageal junction cancer [55]. Additionally, nivolumab is approved in Japan in gastric and gastroesophageal junction cancer [56]. A phase II trial has been conducted testing nivolumab in esophageal squamous cancer [57]. Several other phase III studies are ongoing to evaluate checkpoint inhibitors in earlier treatment lines. One phase II study investigated nivolumab in metastasized anal cancer and showed a response in $24 \%$ of patients. The response was dependent on PD-L1 expression [58]. Disappointing results came from investigations which aimed to introduce immuno-oncological approaches to the treatment of pancreatic cancer [59].

In contrast to colorectal cancer, immunohistochemical PD-L1 expression plays a major role in predicting the response of checkpoint inhibitors. The assessment of PDL1 is complicated by several different guidelines depending on the tumor entities and the different inhibitors. The three currently used assessment regimens are explained in Table 2 and Figure 1. These assessment rules relate to the cell types that must be evaluated or excluded and the cutoff values. In opposite to the European Medicines Agency, the FDA also specifies the immunohistochemical antibodies and the staining platforms.

\section{Conclusion}

Immunotherapeutic approaches can be seen as the currently most promising new concepts in cancer. This is underscored by the Nobel Prize 2018 that went to researchers in this field. In GI cancers only checkpoint inhibitors have yet reached daily routine. The mismatch repair/microsatellite instability status is currently the only relevant predictive marker in colorectal cancer and has been identified as tumor agnostically predictive. In other GI cancers, however, the immunohistochemically determined PD-L1 status is the main predictor for these drugs. There are many more biomarkers under investigation, some of which may become relevant. They most likely ones are POLE and tumor mutational burden.

\section{Statement of Ethics}

The authors have no ethical conflicts to disclose.

\section{Disclosure Statement}

All authors declare that no conflict of interests exists.

\section{References}

1 Torre LA, Bray F, Siegel RL, Ferlay J, LortetTieulent J, Jemal A. Global cancer statistics, 2012. CA Cancer J Clin. 2015 Mar;65(2):87108.

2 Zarkavelis G, Boussios S, Papadaki A, Katsanos KH, Christodoulou DK, Pentheroudakis G. Current and future biomarkers in colorectal cancer. Ann Gastroenterol. 2017; 30(6):613-21.

3 Coley WB. II. Contribution to the Knowledge of Sarcoma. Ann Surg. 1891 Sep;14(3):199220.

4 Smith T. Active immunity produced by so called balanced or neutral mixtures of diphtheria toxin and antitoxin. J Exp Med. 1909 Mar;11(2):241-56.

5 Couzin-Frankel J. Breakthrough of the year 2013. Cancer immunotherapy. Science. 2013 Dec;342(6165):1432-3.

6 Altmann DM. A Nobel Prize-worthy pursuit: cancer immunology and harnessing immunity to tumour neoantigens. Immunology. 2018 Nov;155(3):283-4.
7 Stein A, Moehler M, Trojan J, Goekkurt E, Vogel A. Immuno-oncology in GI tumours: clinical evidence and emerging trials of PD-1/ PD-L1 antagonists. Crit Rev Oncol Hematol. 2018 Oct;130:13-26.

8 Procaccio L, Schirripa M, Fassan M, Vecchione L, Bergamo F, Prete AA, et al. Immunotherapy in Gastrointestinal Cancers. BioMed Res Int. 2017;2017:4346576.

9 Sanmamed MF, Chen L. A Paradigm Shift in Cancer Immunotherapy: From Enhancement to Normalization. Cell. 2018 Oct;175(2):31326.

10 Harbaum L, Pollheimer MJ, Kornprat P, Lindtner RA, Bokemeyer C, Langner C. Peritumoral eosinophils predict recurrence in colorectal cancer. Mod Pathol. 2015 Mar; 28(3):403-13.

11 Wikberg ML, Ling A, Li X, Öberg Å, Edin S, Palmqvist R. Neutrophil infiltration is a favorable prognostic factor in early stages of colon cancer. Hum Pathol. 2017 Oct;68:193202.
12 Waniczek D, Lorenc Z, Śnietura M, Wesecki M, Kopec A, Muc-Wierzgoń M. Tumor-Associated Macrophages and Regulatory T Cells Infiltration and the Clinical Outcome in Colorectal Cancer. Arch Immunol Ther Exp (Warsz). 2017 Oct;65(5):445-54.

13 Hsu YL, Chen YJ, Chang WA, Jian SF, Fan HL, Wang JY, et al. Interaction between Tumor-Associated Dendritic Cells and Colon Cancer Cells Contributes to Tumor Progression via CXCL1. Int J Mol Sci. 2018 Aug; 19(8):E2427.

14 Mayr P, Aumann G, Schaller T, Schenkirsch G, Anthuber M, Märkl B. Lymph node hypoplasia is associated with adverse outcomes in node-negative colon cancer using advanced lymph node dissection methods. Langenbecks Arch Surg. 2016 Mar;401(2):181-8. 
15 Märkl B, Wieberneit J, Kretsinger H, Mayr P, Anthuber M, Arnholdt HM, et al. Number of Intratumoral $\mathrm{T}$ Lymphocytes Is Associated With Lymph Node Size, Lymph Node Harvest, and Outcome in Node-Negative Colon Cancer. Am J Clin Pathol. 2016 Jun;145(6): 826-36.

16 Marshall HT, Djamgoz MB. Immuno-Oncology: Emerging Targets and Combination Therapies. Front Oncol. 2018 Aug;8:315.

17 Guinney J, Dienstmann R, Wang X, de Reyniès A, Schlicker A, Soneson C, et al. The consensus molecular subtypes of colorectal cancer. Nat Med. 2015 Nov;21(11):1350-6.

18 Pino MS, Chung DC. The chromosomal instability pathway in colon cancer. Gastroenterology. 2010 Jun;138(6):2059-72.

19 Brahmer JR, Tykodi SS, Chow LQ, Hwu WJ, Topalian SL, Hwu P, et al. Safety and activity of anti-PD-L1 antibody in patients with advanced cancer. N Engl J Med. 2012 Jun; 366(26):2455-65.

20 Lipson EJ, Sharfman WH, Drake CG, Wollner I, Taube JM, Anders RA, et al. Durable cancer regression off-treatment and effective reinduction therapy with an anti-PD-1 antibody. Clin Cancer Res. 2013 Jan;19(2): 462-8.

21 Le DT, Uram JN, Wang H, Bartlett BR, Kemberling $\mathrm{H}$, Eyring AD, et al. PD-1 Blockade in Tumors with Mismatch-Repair Deficiency. N Engl J Med. 2015 Jun;372(26):2509-20.

22 Le DT, Durham JN, Smith KN, Wang H, Bartlett BR, Aulakh LK, et al. Mismatch repair deficiency predicts response of solid tumors to PD-1 blockade. Science. 2017 Jul;357(6349): 409-13.

23 Overman MJ, McDermott R, Leach JL, Lonardi S, Lenz HJ, Morse MA, et al. Nivolumab in patients with metastatic DNA mismatch repair-deficient or microsatellite instabilityhigh colorectal cancer (CheckMate 142): an open-label, multicentre, phase 2 study. Lancet Oncol. 2017 Sep;18(9):1182-91.

24 Llosa NJ, Cruise M, Tam A, Wicks EC, Hechenbleikner EM, Taube JM, et al. The vigorous immune microenvironment of microsatellite instable colon cancer is balanced by multiple counter-inhibitory checkpoints. Cancer Discov. 2015 Jan;5(1):43-51.

25 Hellmann MD, Ciuleanu TE, Pluzanski A, Lee JS, Otterson GA, Audigier-Valette C, et al. Nivolumab plus Ipilimumab in Lung Cancer with a High Tumor Mutational Burden. N Engl J Med. 2018 May;378(22):2093-104

26 Johnson DB, Frampton GM, Rioth MJ, Yusko E, Xu Y, Guo X, et al. Targeted Next Generation Sequencing Identifies Markers of Response to PD-1 Blockade. Cancer Immunol Res. 2016 Nov;4(11):959-67.

27 Rosenberg JE, Hoffman-Censits J, Powles T, van der Heijden MS, Balar AV, Necchi A, et al. Atezolizumab in patients with locally advanced and metastatic urothelial carcinoma who have progressed following treatment with platinum-based chemotherapy: a singlearm, multicentre, phase 2 trial. Lancet. 2016 May;387(10031):1909-20.

28 Fabrizio DA, George TJ Jr, Dunne RF, Frampton G, Sun J, Gowen K, et al. Beyond microsatellite testing: assessment of tumor mutational burden identifies subsets of colorectal cancer who may respond to immune checkpoint inhibition. J Gastrointest Oncol. 2018 Aug;9(4):610-7.

29 Schumacher TN, Schreiber RD. Neoantigens in cancer immunotherapy. Science. $2015 \mathrm{Apr}$; 348(6230):69-74.

30 Galluzzi L, Buqué A, Kepp O, Zitvogel L, Kroemer G. Immunogenic cell death in cancer and infectious disease. Nat Rev Immunol. 2017 Feb;17(2):97-111.

31 Domingo E, Freeman-Mills L, Rayner E, Glaire M, Briggs S, Vermeulen L, et al.; Epicolon consortium. Somatic POLE proofreading domain mutation, immune response, and prognosis in colorectal cancer: a retrospective, pooled biomarker study. Lancet Gastroenterol Hepatol. 2016 Nov;1(3):207-16.

32 Gong J, Wang C, Lee PP, Chu P, Fakih M. Response to PD-1 Blockade in Microsatellite Stable Metastatic Colorectal Cancer Harboring a POLE Mutation. J Natl Compr Canc Netw. 2017 Feb;15(2):142-7.

33 Schalper KA, Kaftan E, Herbst RS. Predictive Biomarkers for PD-1 Axis Therapies: The Hidden Treasure or a Call for Research. Clin Cancer Res. 2016 May;22(9):2102-4.

34 Galon J, Costes A, Sanchez-Cabo F, Kirilovsky A, Mlecnik B, Lagorce-Pagès C, et al. Type, density, and location of immune cells within human colorectal tumors predict clinical outcome. Science. 2006 Sep;313(5795):1960-4.

35 Mlecnik B, Tosolini M, Kirilovsky A, Berger A, Bindea G, Meatchi T, et al. Histopathologic-based prognostic factors of colorectal cancers are associated with the state of the local immune reaction. J Clin Oncol. 2011 Feb; 29(6):610-8.

36 Kirilovsky A, Marliot F, El Sissy C, Haicheur N, Galon J, Pagès F. Rational bases for the use of the Immunoscore in routine clinical settings as a prognostic and predictive biomarker in cancer patients. Int Immunol. 2016 Aug; 28(8):373-82.

37 Pagès F, Kirilovsky A, Mlecnik B, Asslaber M, Tosolini M, Bindea G, et al. In situ cytotoxic and memory $\mathrm{T}$ cells predict outcome in patients with early-stage colorectal cancer. J Clin Oncol. 2009 Dec;27(35):5944-51.

38 Anitei MG, Zeitoun G, Mlecnik B, Marliot F, Haicheur N, Todosi AM, et al. Prognostic and predictive values of the Immunoscore in patients with rectal cancer. Clin Cancer Res. 2014 Apr;20(7):1891-9.

39 Teng F, Meng X, Kong L, Mu D, Zhu H, Liu $S$, et al. Tumor-infiltrating lymphocytes, forkhead box P3, programmed death ligand-1, and cytotoxic T lymphocyte-associated antigen- 4 expressions before and after neoadjuvant chemoradiation in rectal cancer. Transl Res. 2015 Dec;166(6):721-732.e1.

40 Teng F, Mu D, Meng X, Kong L, Zhu H, Liu $S$, et al. Tumor infiltrating lymphocytes (TILs) before and after neoadjuvant chemoradiotherapy and its clinical utility for rectal cancer. Am J Cancer Res. 2015 May;5(6):206474.

41 Mlecnik B, Bindea G, Angell HK, Maby P, Angelova $\mathrm{M}$, Tougeron $\mathrm{D}$, et al. Integrative Analyses of Colorectal Cancer Show Immunoscore Is a Stronger Predictor of Patient Survival Than Microsatellite Instability. Immunity. 2016 Mar;44(3):698-711.
42 Wirta EV, Seppälä T, Friman M, Väyrynen J, Ahtiainen $\mathrm{M}$, Kautiainen $\mathrm{H}$, et al. Immunoscore in mismatch repair-proficient and -deficient colon cancer. J Pathol Clin Res. 2017 Jul;3(3):203-13.

43 Galon J, Angell HK, Bedognetti D, Marincola FM. The continuum of cancer immunosurveillance: prognostic, predictive, and mechanistic signatures. Immunity. 2013 Jul;39(1): 11-26.

44 Galon J, Pagès F, Marincola FM, Angell HK, Thurin M, Lugli A, et al. Cancer classification using the Immunoscore: a worldwide task force. J Transl Med. 2012 Oct;10(1):205.

45 Galon J, Mlecnik B, Bindea G, Angell HK, Berger A, Lagorce C, et al. Towards the introduction of the "Immunoscore" in the classification of malignant tumours. J Pathol. 2014 Jan;232(2):199-209.

46 Galon J, Fox BA, Bifulco CB, Masucci G, Rau $\mathrm{T}$, Botti $\mathrm{G}$, et al. Immunoscore and Immunoprofiling in cancer: an update from the melanoma and immunotherapy bridge 2015. J Transl Med. 2016 Sep;14(1):273.

47 Galon J, Lugli A, Bifulco C, Pages F, Masucci G, Marincola FM, et al. World-Wide Immunoscore Task Force: meeting report from the "Melanoma Bridge", Napoli, November 30th-December 3rd, 2016. J Transl Med. 2017 Oct;15(1):212.

48 Pagès F, Mlecnik B, Marliot F, Bindea G, Ou FS, Bifulco C, et al. International validation of the consensus Immunoscore for the classification of colon cancer: a prognostic and accuracy study. Lancet. 2018 May;391(10135): 2128-39.

49 Märkl B, Rößle J, Arnholdt HM, Schaller T, Krammer I, Cacchi C, et al. The clinical significance of lymph node size in colon cancer. Mod Pathol. 2012 Oct;25(10):1413-22.

50 Schrembs P, Martin B, Anthuber M, Schenkirsch G, Märkl B. The prognostic significance of lymph node size in node-positive colon cancer. PLoS One. 2018 Aug;13(8):e0201072.

51 Märkl B. Stage migration vs immunology: the lymph node count story in colon cancer. World J Gastroenterol. 2015 Nov;21(43): 12218-33.

52 Cancer Facts \& Figures 2017. Available from: https://www.cancer.org/research/cancerfacts-statistics/all-cancer-facts-figures/cancer-facts-figures-2017.html [accessed November 26, 2018].

53 Hazama S, Tamada K, Yamaguchi Y, Kawakami Y, Nagano H. Current status of immunotherapy against gastrointestinal cancers and its biomarkers: perspective for precision immunotherapy. Ann Gastroenterol Surg. 2018 Jun;2(4):289-303

54 El-Khoueiry AB, Sangro B, Yau T, Crocenzi TS, Kudo M, Hsu C, et al. Nivolumab in patients with advanced hepatocellular carcinoma (CheckMate 040): an open-label, noncomparative, phase $1 / 2$ dose escalation and expansion trial. Lancet. 2017 Jun;389(10088): 2492-502.

55 Fuchs CS, Doi T, Jang RW, Muro K, Satoh T, Machado $\mathrm{M}$, et al. KEYNOTE-059 cohort 1 : efficacy and safety of pembrolizumab (pembro) monotherapy in patients with previously treated advanced gastric cancer. J Clin Oncol. 2017;35 Suppl:4003. 
56 Kang YK, Boku N, Satoh T, Ryu MH, Chao Y, Kato K, et al. Nivolumab in patients with advanced gastric or gastro-oesophageal junction cancer refractory to, or intolerant of, at least two previous chemotherapy regimens (ONO4538-12, ATTRACTION-2): a randomised, double-blind, placebo-controlled, phase 3 trial. Lancet. 2017 Dec;390(10111):2461-71

57 Kudo T, Hamamoto Y, Kato K, Ura T, Kojima T, Tsushima T, et al. Nivolumab treatment for oesophageal squamous-cell carcinoma: an open-label, multicentre, phase 2 trial. Lancet Oncol. 2017 May;18(5):631-9.

58 Morris VK, Salem ME, Nimeiri H, Iqbal S, Singh P, Ciombor K, et al. Nivolumab for previously treated unresectable metastatic anal cancer (NCI9673): a multicentre, single-arm, phase 2 study. Lancet Oncol. 2017 Apr; 18(4): 446-53.

59 Knudsen ES, Vail P, Balaji U, Ngo H, Botros IW, Makarov V, et al. Stratification of Pancreatic Ductal Adenocarcinoma: Combinatorial Genetic, Stromal, and Immunologic Markers. Clin Cancer Res. 2017 Aug;23(15):4429-40.

60 Yaghmour G, Pandey M, Ireland C, Patel K, Nunnery S, Powell D, et al. Role of Genomic Instability in Immunotherapy with Checkpoint Inhibitors. Anticancer Res. 2016 Aug; 36(8):4033-8.
61 Buchhalter I, Rempel E, Endris V, Allgäuer M, Neumann O, Volckmar AL, et al. Size matters: dissecting key parameters for panel-based tumor mutational burden analysis. Int J Cancer. 2019 Feb;144(4):848-58.

62 van Gool IC, Eggink FA, Freeman-Mills L, Stelloo E, Marchi E, de Bruyn M, et al. POLE proofreading mutations elicit an antitumor immune response in endometrial cancer. Clin Cancer Res. 2015 Jul;21(14):3347-55.

63 Schmid P, Hegde PS, Zou W, Kowanetz M, Mariathasan S, Molinero L, et al. Association of PD-L2 expression in human tumors with atezolizumab activity. J Clin Oncol. 2016;34 Suppl:11506.

64 Yearley JH, Gibson C, Yu N, Moon C, Murphy E, Juco J, et al. PD-L2 Expression in $\mathrm{Hu}$ man Tumors: Relevance to Anti-PD-1 Therapy in Cancer. Clin Cancer Res. 2017 Jun; 23(12):3158-67.

65 Inoue Y, Yoshimura K, Mori K, Kurabe N, Kahyo T, Mori $\mathrm{H}$, et al. Clinical significance of PD-L1 and PD-L2 copy number gains in non-small-cell lung cancer. Oncotarget. 2016 May;7(22):32113-28.
66 McGranahan N, Furness AJ, Rosenthal R, Ramskov S, Lyngaa R, Saini SK, et al. Clonal neoantigens elicit $\mathrm{T}$ cell immunoreactivity and sensitivity to immune checkpoint blockade. Science. 2016 Mar;351(6280): 1463-9.

67 Newman AM, Liu CL, Green MR, Gentles AJ, Feng W, Xu Y, et al. Robust enumeration of cell subsets from tissue expression profiles. Nat Methods. 2015 May;12(5):453-7.

68 Wallden B, Pekker I, Popa S, Dowidar N, Sullivan A, Hood T, et al. Development and analytical performance of a molecular diagnostic for anti-PD1 response on the nCounter Dx Analysis System. J Clin Oncol. 2016;34 Suppl: 3034.

69 Hong AM, Vilain RE, Romanes S, Yang J, Smith E, Jones D, et al. PD-L1 expression in tonsillar cancer is associated with human papillomavirus positivity and improved survival: implications for anti-PD1 clinical trials. Oncotarget. 2016 Nov;7(47):77010-20.

70 Kelly RJ. Immunotherapy for esophageal and gastric cancer. Am Soc Clin Oncol Educ Book. 2017;37:292-300. 